\title{
Macrobenthic invertebrates as food for a penaeid shrimp pond farm in Brazil
}

\author{
Paulo Cesar de Paiva ${ }^{1}$, José Roberto Machado Cunha da Silva ${ }^{2}$
}

1 Departamento de Zoologia - Instituto de Biologia - Universidade Federal do Rio de Janeiro. Ilha do Fundão, CCS, Bloco A, 21941-590, Rio de Janeiro, RJ - Brazil. Tel: 55-21-5605993. E-mail: pcpaiva@acd.ufrj.br

2 Departamento de Histologia e Embriologia - Instituto de Ciências Biomédicas - Universidade de São Paùlo, São Paulo,SP - Brazil. Tel: 55-11-8187402. E-mail: jrmcs@usp.br

Received 11-VII-1997. Corrected 9-II-1998. Accepted 11-III-1998.

\begin{abstract}
Resumen: El macrobentos de estanques de cultivo de Penaeus subitilis y Penaeus schmitti se estudió en la costa nordeste de Brasil durante 12 semanas. El poliqueto Laeonereis culveri ( $\left.2433 \mathrm{ind} / 0.1 \mathrm{~m}^{2}\right)$ y el anfípodo Grandidierella bonnieroides $\left(2726 \mathrm{ind} / 0.1 \mathrm{~m}^{2}\right.$ ) fueron intensamente depredados por los peneidos. Ningún individuo de $G$. bonnieroides sobrevivió más de seis semanas: en el tiempo restante $L$. culveri, que también puede reclutarse en el periodo, fue el principal recurso natural alimenticio disponible.
\end{abstract}

Key words: Macrobenthos, shrimp culture, Penaeus, Laeonereis, Grandidierella, natural food.

As the world's crustacean production in cultures increases, the need for an improved knowledge on the structure and functioning of commercial ponds becomes necessary to improve culture's yield. This need is specially strong for the cultures in Third World countries based mainly on extensive and semi-intensive systems where natural food organisms can play a crucial role in the nutrition of fish and shrimp (Tacon 1988). The importance of macrobenthic invertebrates as a source of natural food has been demonstrated (Anderson et al. 1987, Ordner et al. 1990) mainly when combined to supplementary food (Tacon 1988, Galgani et al. 1989). However, there is little knowledge about which species are most appropriate as a food source for this commercially important species. This study is an attempt to relate shifts in macrobenthic community to potential predation by Penaeus spp. shrimps during their growth period in a commercial semi-intensive farm.

The data were gathered in farm from a inside mangrove area in Ceará State, northeastern Brazilian coast. Pond area was $7000 \mathrm{~m}^{2}$ with $0.7 \mathrm{~m}$ mean depth. Before the beginning of the experiment, the pond was kept dry for two days, and fertilized with urea $(21 \mathrm{~kg})$ through the entire cycle. Two species of shrimps were cultivated: Penaeus subtilis and Penaeus schmitti, during a grow out period of 12 weeks (Nov./1988 to Feb/1989) with an initial density of $10 \mathrm{shrimps} / \mathrm{m}^{2}$. The culture was supplied with ration (ca. 5 to $10 \%$ of shrimp biomass) twice a day as usual in commercial farms in the area. Shrimps were sampled with a net for estimation of mean individual weight during the grow out period. 
The macrobenthic sampling was carried out weekly using a $80 \mathrm{~cm}^{2}$ cylindrical corer. Three replicates were collected in three different pond regions: entrance, centre and exit. Another sample was collected in the neighbouring mangrove at the same depth $(0.7 \mathrm{~m})$. Sediment was sieved in a $0.5 \mathrm{~mm}$ mesh, being fixed in a $10 \%$ formalin for sorting and identification. For the biomass measurement of the two dominant species (the polychaete $L$. culveri and the amphipod $G$. bonnieroides) the material was dried at $60^{\circ} \mathrm{C}$ for 24 hours and weighted.

The pond macrofauna was different in composition and richness from the macrofauna of the nearby mangrove. Pond was inhabitated by the polychaetes $L$. culveri, Capitella capitata, Marphysa sp. and Parandalia tricuspis and the amphipod G. bonnieroides, whereas the mangrove was dominated by the polychaetes Heteromastus filiformis and Glycinde multidens. The shrimp biomass variation during the monitoring period and abiotic data are shown in Fig. 1. Water temperature was not measured, but in this season it normally ranges between 25.0 to $31.0^{\circ} \mathrm{C}$.

L. culveri and G. bonnieroides, by far the dominant species with maximum densities of 2 433 and 2726 individuals for $0.1 \mathrm{~m}^{2}$, were monitored during the entire grow out period (Fig. 2). Both the density and the biomass of $G$. bonnieroides decayed during the period being, after Dec./20, almost not found in the sediment. On the other hand, L. culveri, which also decreased in the beginning of the experiment, showed a recruitment in Dec./20, resulting in a biomass recuperation, that was kept stable until Jan./10. After that, no specimens of the polychaete were found in the sediment. Shrimp performance showed a initial increase (first 3 weeks) up to $8 \mathrm{~g}$, then a long period of biomass stability (ca. 4 weeks) was followed by a new growing period, reaching an estimated biomass of $12 \mathrm{~g}$ in three weeks.

The decrease in density and biomass of the main macrobenthic species clearly shows

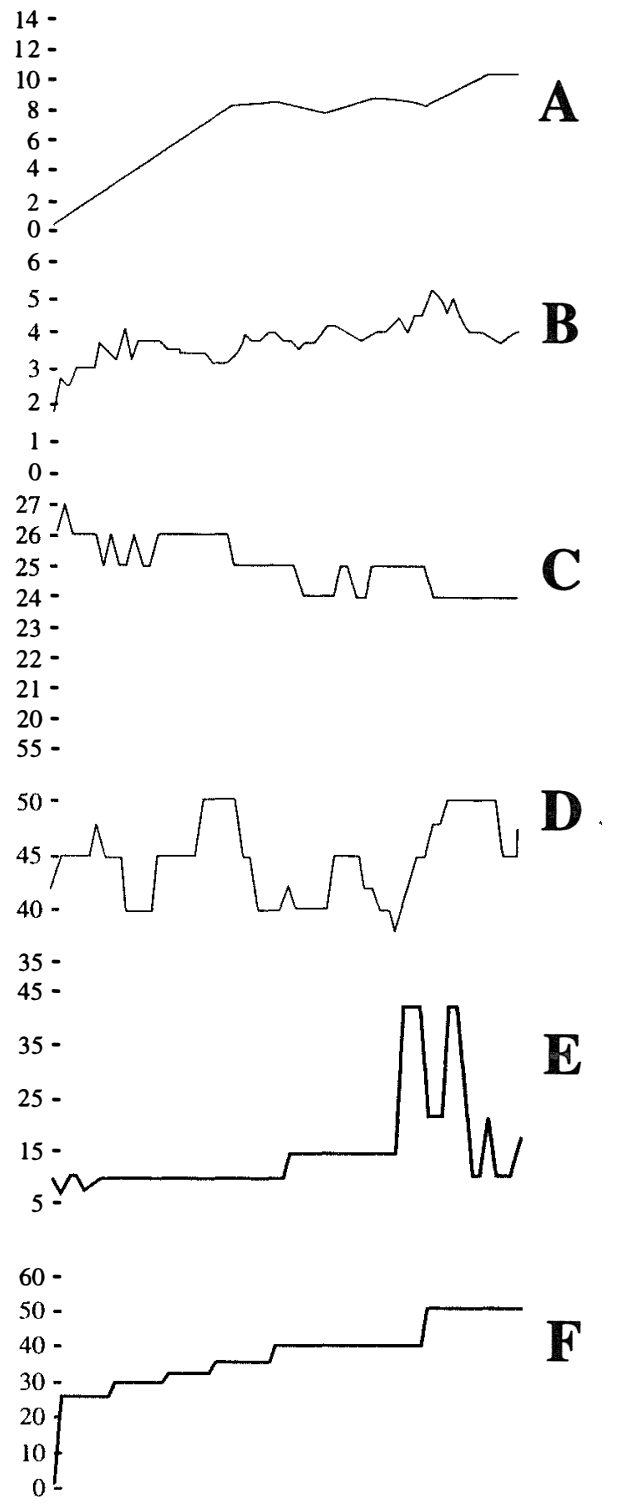

22290613202708101724310714

NOV. DEC. JAN. FEB.

Fig. 1. Shrimp biomass and environmental variables during shrimps grow-out period. A: Shrimp biomass (g); B: Dissolved Oxygen (mg/); C: Salinity; D: Transparency $(\mathrm{cm})$; E: Renew rate (\%) and F: Raion (kg).

the role of shrimp predation on pond biota. The amphipod G. bonnieroides seems to be the first 

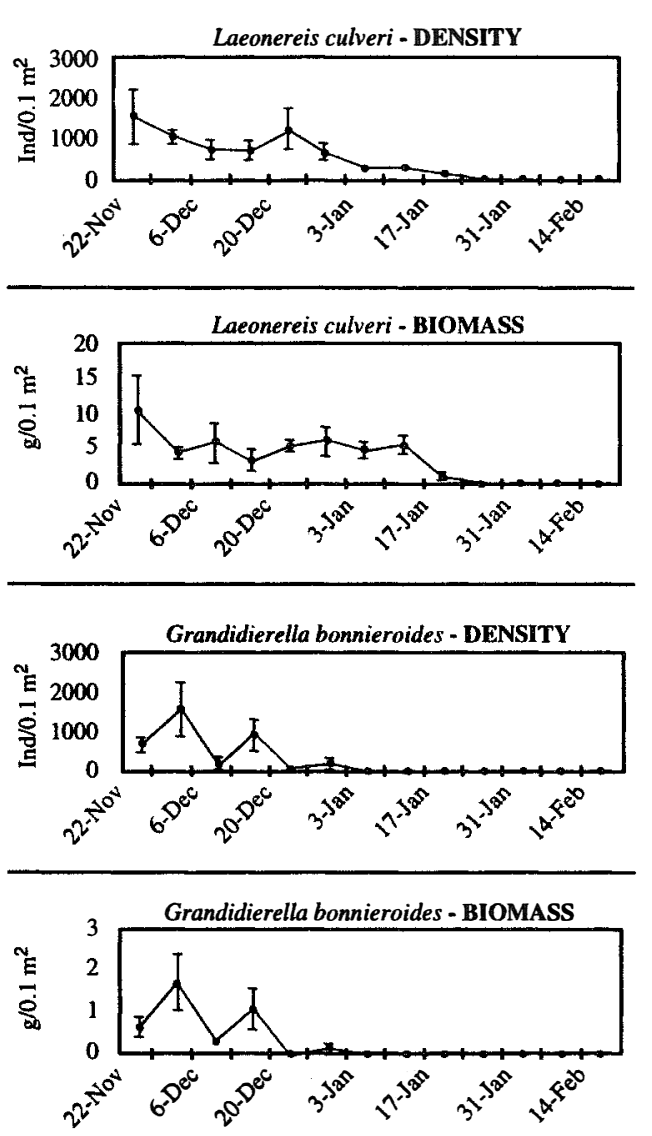

Fig. 2. Average density and biomass (+ standad error) of the polychaete Laeonereis culveri and the amphipod Grandidierella onnieroides during shrimps grow-out period. Biomass expressed as grams of wet weight.

choice of the shrimp, as can be seen from the large fluctuation in biomass and density of the amphipod in the first four weeks. After the $G$. bonnieroides disappearance from the pond, $L$. culveri was the only natural food resource for the shrimp, and thus, the shrimp fed on it intensively only after that. The density fall of L. culveri after the Dec./20 recruitment was not associated to a biomass fall, giving rise to the hypothesis that Penaeus spp. prey first the smaller recently recruited worms not important to overall polychaete biomass. This behaviour is associated to the greater availability of younger worms in the sediment surface
(Bemvenuti 1992). This happened when shrimp biomass was kept stable, thus the stabilisation of shrimp growth does not seem to be related to food availability, but to some other factor linked to pond management. The trigger to higher growth rates matches a strong fall on salinity. After the stabilisation, the shrimp population started to grow again in higher rates and worms of the higher sizeclasses are also preyed decreasing polychetes density until it is completely vanished.

As regards pond management, the pond drying prior to the grow out period seems to control the composition of the biota. $G$. bonnieroides is available in the water column, changing its benthic habit for a pelagic one as a strategy to avoid predation (Stearns \& Dardeau 1990) and, by doing so, it is able to colonise the pond through inflowing water. On the other hand, L. culveri is capable of maintaining its eggs adhered to adults' tubes inside the sediment, being able to survive even when the pond was dry. It is shown herein that L. culveri can be used not only as natural pond food but can be ransplanted for increasing the yield of tropical semi-intensive and extensive cultures. $L$. culveri seems to be an excellent food resource for the shrimp, specially when combined with an increasing fraction of supplementary ration. Exceeding ration supply is available for the shrimp in the form of polychaete biomass avoiding the eutrophication of the pond, as often occurs on semi-intensive shrimp cultures.

\section{REFERENCES}

Anderson, R.K., P.L. Parker \& A. Lawrence 1987. A $13 \mathrm{C} / 12 \mathrm{C}$ tracer study of the utilization of presente feed by a commercially important shrimp Penaeus vannamei in a pond grow out system. J. World Aquacult. Soc. 18: 148-155.

Bemvenuti, C.E. 1992. Interações biológicas da macrofauna bentônica da região estuarial da Lagoa dos Patos, RS, Brasil. PhD Thesis, Universidade de São Paulo, São Paulo, Brasil. 
Galgani, M.L., J. Goguenheim, F. Galgani \& G. Cuzon 1989. Influence du regime alimentaire sur la reproduction en captivite de Penaeus v'annamei et Pencaeus stylirostris. Aquaculture 80: 97-109.

Ordner, M.T., A. Lawrence \& J.W. Tunnel Jr. 1990. Macrobenthos in earthen shrimp ponds in southern Texas. Texas J. Sci. 42: 273-282.
Stearns, D.E. \& M.R. Dardeau 1990. Nocturnal and tidal vertical migaration of "benthic" crustaceans in an estuarine system with diurnal tides. Northeast Gulf Sci. 11: 93-104.

Tacon, A.G.J. 1988 The nutrition and feeding of farmed fish and shrimp - a training manual. 3. Feeding methods. FAO, Brasilia, Brazil. 208p. 